\title{
Configurações
}

Revista de sociologia

14 | 2014

Para além da Governação. Políticas, práticas e discursos de inclusão e promoção da diversidade cultural

\section{Representações de professoras/es de escolas públicas do Rio Grande do Sul/Brasil sobre diversidade cultural}

Representations of Teachers in Public Schools of Rio Grande do Sul, Brazil, on

cultural diversity

Représentations des Professeurs d'écoles publiques de Rio Grande do Sul, Brésil

sur la diversité culturelle

Célia Elizabete Caregnato, Pâmela Marconatto Marques e Gregory da Silva Balthazar

\section{(2) OpenEdition}

\section{Edição electrónica}

URL: http://journals.openedition.org/configuracoes/2233

DOI: 10.4000/configuracoes.2233

ISSN: $2182-7419$

Editora

Centro de Investigação em Ciências Sociais

Edição impressa

Paginação: 25-38

ISBN: 1646-5075

ISSN: 1646-5075

\section{Refêrencia eletrónica}

Célia Elizabete Caregnato, Pâmela Marconatto Marques e Gregory da Silva Balthazar, «

Representações de professoras/es de escolas públicas do Rio Grande do Sul/Brasil sobre diversidade cultural ", Configurações [Online], 14 | 2014, posto online no dia 26 março 2015, consultado o 20 abril 2019. URL : http://journals.openedition.org/configuracoes/2233; DOI : 10.4000/configuracoes.2233

Este documento foi criado de forma automática no dia 20 Abril 2019.

(c) CICS 


\title{
Representações de professoras/es de escolas públicas do Rio Grande do Sul/ Brasil sobre diversidade cultural
}

\author{
Representations of Teachers in Public Schools of Rio Grande do Sul, Brazil, on \\ cultural diversity \\ Représentations des Professeurs d'écoles publiques de Rio Grande do Sul, Brésil \\ sur la diversité culturelle
}

Célia Elizabete Caregnato, Pâmela Marconatto Marques and Gregory da Silva Balthazar

\section{Introdução}

1 A ascensão de governos de esquerda em diversos países latino-americanos no final do século XX e início do século XXI fez com que estejamos testemunhando, nesses cenários, a elaboração de políticas públicas supostamente progressistas, grande parte delas voltada à redução das desigualdades em prol de grupos vulneráveis. As chamadas "políticas identitárias" ganham especial repercussão, já que se trata de espaços marcados pelo rastro colonial vislumbrado no processo de modernidade ocidental, que invisibilizou as relações sexistas e racistas com ela entrelaçadas.

Dentre as políticas adotadas pelo Brasil nesse contexto, interessa-nos o Programa de Educação Continuada de Professores do Ministério da Educação, especialmente no tocante à qualificação de quadros para atuação para e na diversidade cultural. Para tanto, apresentaremos, no presente artigo, alguns resultados situados dessa política, constatados por uma equipe de pesquisa e avaliação criada para acompanhar o Curso de Especialização à Distância em Educação para a Diversidade, voltado a professores/as da rede pública de educação básica, promovido pela Faculdade de Educação da Universidade Federal do Rio Grande do Sul em parceria com a Secretaria de Educação Continuada, 
Alfabetização, Diversidade e Inclusão (SECADI) e com a Universidade Aberta do Brasil, contando com financiamento do Fundo Nacional para o Desenvolvimento da Educação (FNDE) entre os anos 2012 e 2014.

3 O Curso de Especialização em Educação para a Diversidade foi idealizado com o intuito de desacomodar práticas pedagógicas de professoras/es que atuam na rede pública de ensino básico, no sentido de tensionar e romper com alguns preconceitos e normatizações que cercam a presença da diversidade cultural no ambiente escolar. De tal modo, propomos pensar a escola como instituição-chave para o enfrentamento de problemas e entraves à prática democrática, evidenciando como uma educação para e na diversidade cultural reside em um compromisso ético por parte dos sujeitos que compõem a comunidade escolar (Caregnato e Genro, 2013).

4 Partindo do entendimento de que o imaginário dos indivíduos acerca dos grupos sociais inspira seu discurso e prática em relação aos mesmos e de que a escola é um "lugar de discursos que lutam para influenciar o processo de ensino-aprendizagem dos cidadãos e cidadãs" (Joca, 2011: 12), estruturamos o presente texto a partir de dois momentos: primeiramente, exploraremos os resultados de um questionário inicial, aplicado junto ao corpo de professoras/ es-cursistas no início do curso de especialização, em novembro de 2012, cujo foco residiu em uma investigação exploratória acerca das representações dessas/es professoras/es-cursistas em relação às minorias presentes em suas salas de aulas. Em um segundo momento, problematizaremos alguns dados de um questionário aplicado no findar do curso, em junho de 2014, em que se visava compreender como estas/es professoras/es acolheram as discussões realizadas ao longo das disciplinas da especialização, bem como qualificar os obstáculos remanescentes a uma ética das diferenças ${ }^{1}$ e à plena convivência intercultural ${ }^{2}$, pautada, em nossa visão, em uma lógica pós-identitária da educação.

\section{Diversidade étnico-racial em questão}

Nesta primeira etapa investigativa, buscamos averiguar que tipo de representações sobre minorias atravessavam os discursos-ações de professoras/es em salas de aula do estado do Rio Grande do Sul, que estavam ingressando no curso de especialização em educação para a diversidade. De tal modo, dividiu-se o questionário em três eixos - identificação do perfil das/os professoras/es, adesão a discursos/atitudes preconceituosas e conhecimento de práticas discriminatórias no ambiente escolar - cujo conjunto aglutinaram o montante de trinta e oito questões.

6 A coleta de dados seguiu, em ambos os questionários, o método survey, inspirado na pesquisa realizada pela Fundação Instituto de Pesquisas Econômicas (2009: 12), a qual realizou um estudo sobre ações discriminatórias no âmbito escolar, focalizando os temas étnico-racial, de gênero, geracional, territorial, de necessidades especiais (deficiência) e socioeconômico. No nosso caso buscamos identificar a presença e a variação relativas a preconceitos e discriminações, entre as/os quatrocentas/os professoras/es que compõem o universo, utilizando o recurso de assertivas que expressam situações, ações e valores, e que foram respondidas pela escala Likert de quatro pontos, quanto aos níveis de concordância e discordância. Utilizamos a análise estatística descritiva para focalizar os temas de gênero e orientação sexual, e organizamos categorias de respostas por temas, permitindo o estabelecimento de relações entre si e com os elementos que formam o contexto do problema (Flick, 2009) à luz dos estudos pós-coloniais e pós-estruturalistas. 
7 Em relação à primeira categoria de questões (averiguar o perfil dos cursistas), destacamos a última das cinco questões, que solicitava ao respondente que marcasse todas as opções que o identificavam socialmente. As respostas abarcavam gênero, sexualidade, raça e etnia. Em torno de $85 \%$ dos cursistas identificaram-se racialmente, enquanto $15 \%$ optaram por não manifestar-se nesse sentido.

8 Entre aqueles que se identificaram, $80 \%$ se disseram brancos, $10 \%$ pardos, $9 \%$ pretos e $1 \%$ amarelos. Esses índices nos parecem interessantes, não apenas porque confirmam a baixa representatividade de professores não brancos nas escolas gaúchas, mas porque fazem emergir a dúvida em relação aos $15 \%$ que optaram por não identificar-se racialmente. A atitude enseja conjecturas, sendo, então, o foco de questionamento desta primeira parte. Evidenciaria um boicote à segmentação racial e, nesse sentido, uma atitude politicamente inspirada ou apenas receio de que a identificação nesse nível pudesse comprometê-los de alguma forma?

Em relação à segunda categoria, Questões destinadas à averiguação da adesão a discursos/ atitudes preconceituosas, destacamos que, no universo das dezoito questões, sete referem-se à diversidade racial e serão analisadas a partir de agora. Optamos por dividi-las entre aquelas que evidenciam discursos de ódio, em que o preconceito está escancarado, e aquelas em que ele está envolvido por uma aparente benevolência, aparecendo de forma mais sutil. Lembramos que a compreensão de que o preconceito não está somente na "demonização do outro" mas também na sua "docilização" tem sido uma importante contribuição dos estudos pós-coloniais (Bhabha, 2010; Gilroy, 2001; Costa, 2006) para pensar a questão racial e, especialmente, a educação antirracista.

Homi Bhabha (2010: 98) afirmou a "docilização dos corpos" como prática empenhada em destituir grupos/indivíduos de sua potência, reduzindo-os a corpos "carentes", que tudo necessitam e nada podem. Assim, apesar de uma aparente benevolência, esses discursos em nada contribuem para uma educação democrática e antirracista, na medida em que também estão sustentados em estereótipos. Nesse caso, a redução do outro a alguém de quem o grupo majoritário deve "apiedar-se" reforça a assimetria dos lugares de poder ocupados por um e outro, assim como a ideia de que esse grupo hegemônico deve "tolerar" o minoritário no que lhe falta.

11 Quanto à representação de ódio, ou aquelas em que fica mais evidente o discurso preconceituoso, começaremos analisando a primeira frase submetida à avaliação dos respondentes, que dialoga com os estigmas de que não brancos seriam "sujos" ou teriam "mau cheiro": Reconhecer que a pele negra e a parda possuem odor mais forte que a branca nos leva a priorizar o ensino de hábitos de higiene entre esses alunos. Apesar do alto índice de repúdio máximo à frase apresentada (discordo muito), o grupo auto-identificado como não-branco superou o geral em cerca de $10 \%$, apresentando $86 \%$ de repúdio à frase. Em relação àqueles que disseram concordar muito, dentre os $3 \%$ que marcaram resta resposta, apenas dois são provenientes de auto-identificados como não-brancos.

12 O estigma em jogo na frase subsequente dizia respeito ao parâmetro de avaliação meritocrática do desempenho de um indivíduo em dada sociedade. Ela afirmava que: $\mathrm{A}$ discriminação racial é um problema da familia e do próprio aluno que não aceita sua raça, não lutando por espaço na sociedade e conformando-se com a exclusão. Tal julgamento tem o condão de culpabilizar o membro de grupo minoritário por sua condição de exclusão, abrindo mão de qualquer avaliação mais complexa das condições psicossociais que lhe atravessam e constituem. Também se evidencia o distanciamento do indivíduo que julga em relação 
ao grupo minoritário sobre o qual emite o julgamento, emergindo a conclusão de que aquele "esforçou-se e venceu por seu próprio mérito".

Nota-se que o repúdio máximo em relação a essa frase encontrou bem menor adesão do que a primeira analisada. Quando agrupados, entretanto, os percentuais de adesão à frase (concordo pouco e concordo muito) beiram os 30\%, o que nos parece bastante preocupante. Entre a população auto-identificada como não-branca, o índice máximo de repúdio (discordo muito) chega a ser $10 \%$ maior do que o verificado no grupo geral.

A próxima frase a ser analisada - Alunos negros são mais violentos que alunos indígenas - diz respeito ao estigma que associa a raça negra a uma tendência exacerbada à violência ${ }^{3}$. Ao mesmo tempo, jogamos com o estigma do "bom selvagem" associado aos indígenas, de que seriam "puros e indefesos". Percebe-se que o repúdio à frase foi bastante intenso (82\%), restando apenas $10 \%$ de acolhimento. Entre os fatores que, imaginamos, possam ter influenciado esse resultado, apontamos o fato de que a grande maioria dessas/es professoras/es (70\%) atua no ensino infantil ou fundamental e, dessa forma, não vê seus alunos negros como potenciais agressores, mas como vítimas, associados às suas carências. Como observaremos a partir de agora, a mudança no padrão de respostas quando começamos a analisar as questões caracterizadas pelo discurso preconceituoso mais sutil parecem confirmar essa hipótese.

Quando perguntados sobre o fator primordial de discriminação no Brasil, por meio da frase - Temos consciência de que há racismo no Brasil, porém, o fator socioeconômico sempre fala mais alto e quando um negro ascende na escala social é tratado como branco--, mais de 50\% das/ os professoras/es manifestaram concordar que se trata de preconceito social; ou seja, quando um negro ascende na escala econômica estaria plenamente livre do preconceito. Entre o segmento auto-identificado como não-branco, o padrão de respostas não se altera significativamente, o que evidencia que mesmo entre vítimas potenciais de preconceito racial há dúvida sobre a natureza da exclusão sofrida.

Para pensarmos acerca do trabalho destas/es docentes sobre diversidade étnica-racial na escola, as/os cursistas tiveram de manifestar-se acerca da seguinte frase - 0 professor não deve enfatizar a presença de diversidade racial na sala de aula, pois vivemos num país miscigenado, onde as raças convivem em perfeita harmonia -, na qual colocamos em jogo o mito da harmonia racial brasileira. Apesar do sobressaliente repúdio à frase, manifesto pela maioria dos respondentes, ainda verifica-se que $22 \%$ das/os professoras/es (mais de 80 , portanto) disseram concordar pouco ou muito com seu conteúdo. Entre o segmento de não-brancos, o repúdio à frase é significativamente maior, alcançando $85 \%$ das/os respondentes. Entretanto, verifica-se também que 5\% desse segmento optaram por não responder à questão, enquanto $10 \%$ manifestaram alguma adesão à frase.

Quando perguntadas/os sobre o trabalho em sala de aula em relação à diversidade étnica presente no território brasileiro, mais de $65 \%$ das/os professoras/es respondentes concordaram (pouco ou muito) com a afirmação de que - Na sala de aula é importante abordarmos aspectos culturais referentes à diversidade étnica presente no nosso território, deixando claro, entretanto, que a nossa nacionalidade está acima de todas as diferenças. A essa noção "integradora" do outro sob o manto da nacionalidade subjaz o esfacelamento da diversidade, reduzida e moldada até seu desaparecimento, lembrando os ideais de miscigenação progressiva entre pretos e brancos que levariam à extinção dos primeiros na geração seguinte ao mulato ${ }^{4}$. Mais: por trás dessa concepção está o pressuposto de uma nacionalidade homogênea, que apenas relaciona-se com o diverso a partir de sua integração e não de seu reconhecimento. 

das/os cursistas em relação a situações de discriminação no ambiente escolar. Quando questionadas/os sobre situações em que um/a professor/a negro/a foi tratado/a pela direção da escola de maneira preconceituosa, $81 \%$ das/os respondentes indicaram jamais ter visto ou ouvido em sua escola alguma situação dessas, enquanto $10 \%$ indicaram terem presenciado. Entre as/os professoras/es identificadas/os como não-brancos, o índice daquelas/es que não viram e nem ouviram falar de casos de preconceito desse tipo reduzse para cerca de $70 \%$. respondentes indicaram jamais terem visto ou ouvido falar de uma situação dessas em sua escola, enquanto $14 \%$ manifestaram ter presenciado cenas desse tipo. Entre as/os nãobrancas/os, o índice daquelas/es que viram acontecer essas cenas em sua escola sobe para cerca de $20 \%$. Sobre uma vigilância mais intensa direcionada às/aos alunas/os negras/os por parte das/os funcionárias/os, $81 \%$ das/os respondentes indicaram jamais ter visto ou ouvido falar de caso semelhante em sua escola, enquanto $10 \%$ indicaram ter presenciado cenas do tipo. Entre as/os respondentes não-brancos, mais de 15\% indicaram já as ter visto em sua escola.

É interessante ver que, no conjunto das respostas acima, a representação das/os professoras/es sobre acontecimentos discriminatórios e/ou preconceituosos relativos às/ aos negras/os no ambiente escolar é de fato bastante reduzida. Esse raciocínio leva à interpretação de que o problema, reconhecido como presente na sociedade, não ocorreria na escola porque esta conseguiria estar "isenta" dessa presença ou, ainda, porque não há pessoas negras no seu interior. Certamente o fato de se referir a um estado da região sul do Brasil, com presença significativa de descendentes de imigrantes europeus, contribui para essa representação. Contudo, paralelo ao fato de que proporcionalmente há menor incidência de afrodescendentes no Rio Grande do Sul em relação ao país, trabalhamos com a hipótese de que também se torna mais difícil reconhecer o problema que tende a ocorrer com o outro (o negro) e não consigo (descendente de imigrantes brancos) ou quando cometido pelos "seus".

21 Partindo dos resultados deste primeiro questionário, foi possível constatar que, mesmo entre professoras/es supostamente interessadas/os no tema da diversidade (já que matriculadas/os na Especialização em Educação para a Diversidade), apresentam-se vários obstáculos à afirmação positiva das diferenças e à plena convivência intercultural, pautada em uma lógica não etnocêntrica. Esses obstáculos estão não somente no ódio racial (que, felizmente, já não encontra mais as condições morais de difusão impune que já conheceu), mas no discurso benevolente, na tendência à retificação da cultura/raça $\mathrm{e}$ no discurso meritocrático. Percebemos que, através deles, a diversidade é percebida num discurso de "docilização dos corpos" (Bhabha, 2010) e a diferença é concebida como sinônimo de desigualdade, devendo ser integrada até sua homogeneização.

\section{Gênero e sexualidade: obstáculos para uma educação na e para a diversidade}

O segundo questionário, aplicado ao findar do curso, visou apreender a relação entre as/ os professoras/es-cursistas com nossa proposta de fomentar uma postura pedagógica pautada em uma aposta ética pela diferença. Para tanto, objetivamos demonstrar as 
contradições e estranhamentos que marcam os posicionamentos dos sujeitos pesquisados em torno da diversidade cultural, especialmente de gênero e de orientação sexual, cujas questões aparecem como um foco de maior preocupação das/os professoras/es. o questionário foi estruturado em três eixos - perfil da/o cursista, sensibilidade à diversidade e avaliação do curso (este não será explorado no presente texto). Na sondagem mais técnica do perfil de nossos/as respondentes, solicitamos às/aos mesmas/os que se identificassem em relação às opções de identificação racial, de gênero e orientação sexual. Em relação à identificação de gênero, $10 \%$ das/os respondentes identificaram-se como homens e $89 \%$ como mulheres, restando apenas três professoras/es que optaram por não se identificar e uma aluna transsexual. Em relação à orientação sexual, $60 \%$ do total de respondentes identificaram-se de algum modo. Dentre estes, 93\% declararam-se heterossexuais, $4 \%$ homossexuais e $2,5 \%$ bissexuais. Ressaltamos que $40 \%$ das/os cursistas preferiram não se identificar nesse sentido.

Nosso curso tende a ver que a recusa à identificação da sexualidade pode ser uma postura política, ativa e engajada e não mera omissão, visão que retira a potência que há nos silêncios, nas rasuras, nos espaços em branco. Entretanto, não estamos certos de que esse seja o caso aqui. Salta aos olhos que o eixo de identificação dessas/es cursistas é o gênero. O fato de $99 \%$ das/os respondentes declararem-se homem ou mulher pode evidenciar a persistência da normatividade que incide nas identidades e a força da biologicização das visões do que é ser homem e do que é ser mulher. Parece não haver julgamento ou dúvida pesando sobre essa possibilidade de identificação.

o desconforto das/os cursistas sobre a sexualidade, nesse sentido, pode ser fruto da crença filosófica de uma separação incontestável entre o corpo e a mente, um dualismo que, segundo Bell Hoocks (2010: 114), faz ficticiamente da escola um lugar onde o corpo deve ser anulado, esquecido, para nos entregarmos inteiramente à mente. Ao tomar tal posicionamento, a instituição escolar se recobre de um silêncio que entrava as possibilidades de uma educação voltada para a produção das diferenças culturais; não no sentido de uma hipótese repressiva acerca das identidades sexuais e de gênero, mas sim de um silêncio político, produtor de identidades imbricadas às redes de saber-poder.

Nesse prisma, podemos pensar a escola como uma instância privilegiada de formação das identidades de gênero e de sexualidade, uma vez que, como alertou Foucault (1988), as instituições modernas asseguram uma intensa proliferação discursiva sobre o desejo, o corpo e o sexo, valorizando-os como o segredo. Isso pode ser vislumbrado em algumas respostas dos/das professores/as a questões cujo intuito era perscrutar suas representações de gênero e sexualidade na escola. Cerca de 30\% dos/das respondentes disseram concordar pouco ou muito com a afirmação $A$ educação sexual deve responder à realidade, ajudando, por exemplo, a conscientizar as meninas de que se usarem roupas curtas $e$ tiverem comportamento liberal não poderão, mais tarde, reclamar de possíveis abusos. Além de uma identificável atitude machista, que prega o controle do corpo e do desejo da mulher, percebemos que há uma reivindicação da "discrição" como virtude, um corpo que não deseje e tampouco fique "despertando desejos" em um lugar construído como asséptico, como a escola.

27 Cerca de $60 \%$ das/os respondentes disseram concordar pouco ou muito com a afirmação Aceito bem a existência de casais homossexuais na escola e acredito que apenas suas manifestações públicas de afeto causem constrangimento. Por fim, 45\% das/os respondentes disseram concordar pouco ou muito com a afirmação Aceito meus alunos homossexuais, os considero 
pessoas normais e procuro não tocar no tema em sala de aula para não constrangê-los. Percebe-se aí a atitude benevolente que "não condena" a/o homossexual desde que ela/ele não aja como tal, ou seja, desde que preserve o "segredo".

Aparentemente, portanto, ao buscar-se essas atitudes assépticas, a diferença é construída como algo que se encontra fora dos muros da escola, (re)forçando um discurso homogeneizante na ação educacional cotidiana, cujos agentes se ocupam com a vigilância e regulação dos sintomas da diversidade cultural sustentados por uma noção singular, legítima e normal de gênero e sexualidade - a heteronormatividadade.

(...) em nossas escolas, as ciências e os mapas, as questões matemáticas, a narrativas históricas ou os textos literários relevantes sempre assumem tal identidade como referência. A contínua afirmação e reafirmação deste lugar privilegiado nos faz acreditar em sua universalidade e permanência; nos ajuda a esquecer seu caráter construído e nos leva a lhe conceder a aparência de natural. Todas produções da cultura construídas fora deste lugar central assumem o caráter de diferentes e, quando não são simplesmente excluídas dos currículos, ocupam ali a posição do exótico, do alternativo, do acessório. (Louro, 2003: 44)

As práticas pedagógicas reforçam, portanto, o lugar central que a convergência das identidades masculina, branca, heterossexual, de classe média e cristã ocupam em nossa cultura. Para Foucault (1988), a marca da abjeção, como as perversões sexuais, torna-se um efeito-instrumento; ou seja, a eclosão e a proliferação de saberes sobre a sexualidade produzem o outro, o anormal, estabelecendo uma rede de forças que consolida o lugar daquele que exerce poder como normal, natural.

Ao tentar romper este silêncio político, as diferenças têm integrado, pela denúncia de movimentos sociais e políticas públicas, o currículo de muitas escolas, mas a reposta a essas reivindicações se dá a partir da ideia da inclusão e da tolerância (Skliar, 2004; VeigaNeto, 2001); um reconhecimento da diferença que não chega a perturbar ou desestabilizar os programas já estabelecidos (Louro, 2003; Silva, 2000). Em nossa perspectiva, essa conjectura se alinha ao pensamento de Judith Butler (2010), uma vez que, para a autora, o reconhecimento de uma vida caracteriza-se como uma prática; então, a reconhecibilidade constitui-se enquanto conjunto de convenções e categorias que preparam e modelam o ser humano para o reconhecimento; logo, as normas transformam os indivíduos em sujeitos reconhecíveis. Nesses termos, tão somente "reconhecer" as diferenças não possui força política para uma educação para e na diversidade, uma vez que esta visa fraturar o lugar político construído para as identidades marginais.

31 Nesse contexto, reconhecer o "outro" é dar-lhe um lugar estritamente retórico, reforçando o poder de um "eu", igual e central, sobre um "outro", diferente e marginal. A diferença perde, aqui, seu potencial contestador, criador e ético, sendo, nos termos de Foucault (1987), docilizada, reprodutora dos discursos dominantes, tornando-se economicamente produtiva. Por exemplo, questionadas/os sobre situações em que foram vítimas de preconceito, $32 \%$ das/ os cursistas disseram nunca terem-se sentido alvo dele. O perfil dessas/es respondentes, entretanto, é absolutamente normativo: são homens e mulheres brancos/as e heterossexuais (apenas dois pardos entre eles) discursando em sala de aula sobre diferença e reconhecimento sem terem sido vítimas de preconceito.

Como, então, propor uma educação potencializadora de estratégias pedagógicas de valorização da diferença, reforçando a luta antirracista/antissexista e questionando as relações baseadas em preconceitos e comportamentos discriminatórios? Como enfrentar os obstáculos a uma ética das diferenças e à plena convivência intercultural, se as/os 
professoras/es supostamente interessadas/os no tema da diversidade preconizam uma política do mero reconhecimento da mesma?

Como evidenciamos, o reconhecimento da diferença tem-se constituído como um instrumento para as/os professoras/es-cursistas operarem uma perspectiva de educação para e na diversidade. Por meio de uma lógica identitária, a prática pedagógica do reconhecimento - que também é observável na primeira parte deste texto - convoca a diferença a proferir uma verdade sobre si, reconhecer-se como outro, por meio de uma lógica normatizadora que não questiona mas reforça o lugar de identidades-referência. A partir dos apontamentos de Foucault, podemos inferir que a escola convida, pela política do reconhecimento, os seres humanos a uma relação assujeitadora com a verdade, exercendo um poder que "categoriza o indivíduo, marca-o com sua própria individualidade, liga-o à sua própria identidade, impõe-lhe uma lei de verdade, que devemos reconhecer e que os outros têm de reconhecer nele. É uma forma de poder que faz dos indivíduos sujeitos" (Foucault, 2010b: 278).

A ideia butleriana de apreensão, enquanto base de uma crítica às normas que produzem o reconhecimento, torna-se um conceito importante para a construção de uma educação para e na diversidade, pois a apreensão:

(...) pode implicar o marcar, registrar ou reconhecer sem pleno reconhecimento. Se for uma forma de conhecimento, está associada com o sentir e o perceber, porém, de uma maneira que não é sempre - ou, todavia, não - uma forma conceitual de conhecimento. 0 que podemos apreender vem, sem dúvida, facilitado pelas normas do reconhecimento; contudo, seria um erro afirmar que estamos completamente limitados pelas normas do reconhecimento em curso quando apreendemos uma vida. (Butler, 2010: 19)

Apreender a diferença é conhecê-la, não nos termos normativos do reconhecimento, da contemplação da pluralidade, mas problematizando as disputas, as negociações e conflitos constitutivos das produções dos indivíduos como sujeitos de gênero, sexualidade, raça, etnia e classe. Uma prática pedagógica e um currículo compromissados a apreender as diferenças, portanto, potencializariam a visualização dos jogos de verdade imbricados na construção das identidades que marcam o lugar do eu e do outro, possibilitando um pensar diferente, capaz de fraturar os dispositivos de saber-poder que nos educam, nos transformam, nos marcam, enquanto sujeitos.

Nestes termos, a educação para e na diversidade se aproximaria da proposta política foucaultiana da estética da existência, em inventar-nos a nós mesmas/ os eticamente, transformar esteticamente, a partir de outra relação com a verdade e com outro, o eu singular, fazendo de nossas próprias vidas uma obra de arte. Logo, a estética da existência só é possível como devir na prática pedagógica quando desconstrói as representações sociais que criam e impõem identidades, provocando as/os partícipes do processo educacional a tornarem-se sujeitos de si mesmos a partir da convivência com o outro (Foucault, 1984; Larrosa, 2010; Marcello e Fischer, 2014).

No âmbito do gênero e da sexualidade, assumir uma postura queer para uma educação na e para a diversidade, por exemplo, fomentaria uma prática pedagógica da apreensão da diferença, trabalhando com a produção, a precariedade e a instabilidade das identidades. Assumir um compromisso pedagógico alinhado ao queer é ir além do incluir e reconhecer a diversidade, pois o queer nos convoca a explorar a transgressão e o atravessamento das fronteiras; ou seja, "contrapõe-se, seguramente, à segregação e ao segredo experimentados pelos sujeitos 'diferentes' (...), quer discutir (desmantelar) a lógica que 
construiu esse regime, (...), que mantém e fi xa as posições de legitimidade e ilegitimidade" (Louro, 2008: 51-52).

Sob este prisma, uma educação para e na diversidade comprometida politicamente com as possibilidades éticas da não-identidade rompe, em nossa visão, com a lógica apaziguadora e retórica do reconhecimento, que acaba, como evidenciamos, por retificar e fortalecer relações de subordinação. Em outras palavras, uma proposta pedagógica que visa fomentar outras relações com nós mesmos e com os outros permite, a nosso ver, promover formas de vida mais éticas e autônomas dentro e fora do espaço escolar. Tal empreendimento pressupõe problematizar as próprias formas por meio das quais nos reconhecemos enquanto sujeitos, no sentido de possibilitar um pensar diferente, em outras formas de existência e/ou reconhecer entraves e limitações. Isso se torna imperioso ao voltarmos novamente aos resultados dos questionários avaliados.

Ao sondarmos as/os cursistas sobre situações em que foram agentes de preconceito, verificamos que $96 \%$ reconhecem que já o fizeram, a maioria em relação à orientação sexual. Vemos, aí, que um dos impactos mais importantes do curso pode ter sido o de revelar às/aos suas/seus cursistas uma identidade pessoal de difusores de preconceito até então negada ou não percebida. Acreditamos, inclusive, que a perplexidade ante a imagem de si como um agente difusor de preconceito possa ter sido ainda mais potente $\mathrm{e}$ transformadora do que o simples reconhecimento discursivo da diferença, que não se traduz necessariamente em ação engajada nesse reconhecimento. Essa desconstrução de si como suposto "agente de reconhecimento" possibilitaria, na lógica pós-identitária, um maior cuidado sobre seu discurso/prática, um "escutar-se falar com o outro" e um "observar-se agir em meio a outros" que, em nossa perspectiva, podem ser atitudes potentes em direção à interculturalidade.

\section{Considerações finais}

Por meio dos resultados coletados no questionário, verificamos que, mesmo entre professores/as supostamente interessados/as no tema da diversidade, apresentam-se vários obstáculos a uma ética das diferenças e à plena convivência intercultural, pautada, em nossa visão, em uma lógica pós-identitária da educação. Muito se avançou, no curso, para o compromisso ético das/os cursistas em colocar em debate as diferenças, tendo em vista o fato de trabalharem com a formação do indivíduo para o convívio social. Logo, nossa proposta pedagógica objetivou destacar a importância do tema da diversidade cultural para a desnaturalização das relações sociais e educacionais na escola, numa perspectiva que contribuísse para o autoquestionamento das/os professoras/es diante das desigualdades sociais.

41 Buscamos assim estimular as/os nossas/os cursistas a se colocarem como disseminadoras/es de um pensamento libertário e democrático, visando à construção de uma sociedade pautada em relações produtivas entre culturas ou modos de ser e se comportar, valorizando deste modo os espaços de convivência pública entre pessoas incluindo todos os sujeitos da educação escolar - com práticas, visões de mundo e comportamentos sociais diferentes entre si.

42 Contudo, identificamos, por meio dos questionários aqui analisados, como a inquestionada ligação entre diferença e identidade tornou-se um obstáculo para uma efetiva educação para e na diversidade cultural. As identidades levaram as/os cursistas a 
se prenderem entre o binômio discursos de ódio-discursos benevolentes, uma postura que tende à reificar o lugar da diferença em uma posição subalterna. Percebemos que, através deles, a diversidade é percebida num discurso de "docilização dos corpos" (Bhabha, 2010; Foucault, 1997), que "adaptando-se", "comportando-se bem", são "aceitos". A diferença é concebida como sinônimo de desigualdade, devendo ser integrada até sua homogeneização, até que o/a aluno/a não possa ser percebido/a em sua diversidade; até que sua diferença não seja capaz de alterar a dinâmica de uma sala de aula pautada pelo paradigma da normalidade e da "pacifi cação", sem diferenças e sem conflitos, mantendose, assim, diferente da vida e cerceadora de vida.

\section{BIBLIOGRAPHY}

BHABHA, Hommi K. (2010), O local da cultura. Belo Horizonte: UFMG.

BUTLER, Judith (2010), Marcos de Guerra: Las vidas lloradas. Buenos Aires: Paidós.

CANCLINI, Néstor Garcia (2007), Diferentes, desiguais e desconectados. Rio de Janeiro: UFRJ.

CAREGNATO, Célia Elizabete e GENRO, Maria Elly (2013), “Educação na e para a diversidade: nexos necessários", in Célia Caregnato e Luiz Bonbassaro, Diversidade cultural: Viver diferenças e enfrentar desigualdades na escola. Erechim: Novello \& Cabonelli, pp. 21-34.

COSTA, Sergio (2006), Dois Atlânticos: Teoria social, anti-racismo, cosmopolitismo. Belo

Horizonte: UFMG.

DELEUZE, Giles (2013), Conversações. São Paulo: Editora 34.

FANON, Frantz (2008), Pele negra, máscaras brancas. Salvador: Edufba.

FLICKS, Uwe (2009), Desenho da pesquisa qualitativa. Porto Alegre: ArtMed/Bookman.

FUNDAÇÃO INSTITUTO DE PESQUISAS ECONÔMICAS (2009), Relatório analítico final: projeto de estudo sobre ações discriminatórias no âmbito escolar, organizadas de acordo com áreas temáticas, a saber, étnico-racial, gênero, geracional, territorial, necessidades especiais, socioeconômica e orientação sexual. São Paulo: MEC/INEP, 2009. Disponível em: portal.mec.gov.br/dmdocuments/relatoriofi nal.pdf. Acesso em 03/03/2011.

FOUCAULT, Michel (2010a), A hermenêutica do sujeito. São Paulo: Martins Fontes.

FOUCAULT, Michel (1988), História da sexualidade v. 1: A vontade de saber. Rio de Janeiro: Editora Graal.

FOUCAULT, Michel (1984), História da sexualidade v. 2: 0 usos dos prazeres. Rio de Janeiro: Editora Graal.

FOUCAULT, Michel (2010b), “O sujeito e o poder”, in Hubert Dreyfus e Paul Rabinow, Michel Foucault. Rio de Janeiro: Forense Universitária.

FOUCAULT, Michel (1987), Vigiar e punir: História das violências nas prisões. Petrópolis: Editora Vozes. 
GILROY, Paul (2001), O Atlântico negro. Modernidade e dupla consciência. São Paulo, Rio de Janeiro: 34/Universidade Cândido Mendes - Centro de Estudos Afro-Asiáticos.

HOOCKS, Bell (2010), “Eros, erotismo e processos pedagógicos”, in Guacira Louro, O corpo educado: Pedagogias da sexualidade. Belo Horizonte: Autêntica, pp. 113-123.

JOCA, Alexandre Martins (2011), "Direitos humanos e diversidade sexual: pelo direito à educação e à diversidade na escola", Salto para o futuro - Educação e diversidade sexual, Ano XXI, Boletim 04, $\mathrm{s} / \mathrm{p}$.

LARROSA, Jorge (2002), "Tecnologias do eu e educação", in Tomaz Tadeu da Silva, O sujeito da educação. Petrópolis: Vozes, pp. 35-86.

LOURO, Guacira Lopes (2003), “Currículo, gênero e sexualidade - Refl etindo sobre o 'normal', o 'diferente' e o 'excêntrico”, in Guacira Louro, Jane Neckel e Silvana Goellner, Corpo, gênero e sexualidade: Um debate contemporâneo na educação. Petrópolis: Editora Vozes, pp. 41-52.

LOURO, Guacira Lopes (2008), Um corpo estranho: Ensaios sobre a sexualidade e a teoria queer. Belo Horizonte: Autêntica.

MARCELLO, Fabiana de Amorim e FISCHER, Rosa Maria Bueno (2014), "Cuidar de si, dizer a verdade: arte, pensamento e ética do sujeito”, Pró-Posições, v. 25 (74), pp. 157-175.

SILVA, Tomaz Tadeu da (2000), "A produção social da identidade e da diferença”, in Tomaz Tadeu da Silva, Identidade e diferença: A perspectiva dos estudos culturais. Petrópolis: Vozes, pp. 73-102.

SKLIAR, Carlos ( 2004), "A materialidade da morte e o eufemismo da tolerância”, in Sílvio Gallo e Regina Souza, Educação do preconceito: Ensaios sobre poder e resistência. São Paulo: Alínea, pp. 69-90.

VEIGA-NETO, Alfredo (2001), "Incluir para excluir", in Jorge Larrosa e Carlos Skliar, Habitantes de Babel: Políticas e poéticas da diferença. Rio de Janeiro: DP\&A, pp. 105-118.

\section{NOTES}

1. Pensamos a dimensão ética da diversidade a partir dos últimos trabalhos de Michel Foucault (2010a: 225), em que o filósofo pontua a fundamental necessidade de uma ética do eu na atualidade: “(...) uma tarefa urgente, fundamental, politicamente indispensável, se for verdade que, afinal, não há outro ponto, primeiro e último, de resistência ao poder político senão na relação de si para consigo". Para Deleuze (2013: 129-130), a ética de Foucault se constrói em paradoxo à moral, uma vez que esta se "apresenta como um conjunto de regras coercitivas de um tipo especial, que consiste em julgar ações e intenções referindo-as a valores transcendentes (é certo, é errado...); a ética é um conjunto de regras facultativas que avaliam o que fazemos, o que dizemos, em função do modo de existência que isso implica". Tal postura ética depende de um trabalho estético cotidiano de si sobre si mesmo, mas que só se torna possível na convivência com o outro.

2. A expressão, enfatizada por Nestor Canclini em seu vasto trabalho sobre interculturalidade, refere-se "à convivência democrática entre diferentes culturas nos processos e dinâmicas sociais, buscando a integração entre elas sem anular sua diversidade e o potencial criativo e vital resultante das relações entre os diferentes e seus respectivos contextos" (Canclini, 2007: 22).

3. Em "Pele negra, máscaras brancas", o martinicano Franz Fanon (2008) discute demoradamente esse estigma em particular.

4. O quadro "A redenção de Cam" de Modesto Brocos (1895), em que a velha matriarca negra ergue suas mãos para o céu, agradecendo o nascimento de sua neta branca, fi lha de sua fi lha mulata com seu genro branco, é bastante ilustrativo desse ideal. 


\section{ABSTRACTS}

O presente trabalho visa problematizar, por meio de dados coletados com professoras/es de escolas da rede pública de ensino do estado do Rio Grande do Sul/Brasil, os obstáculos a uma ética das diferenças e à plena convivência intercultural pressupostas em uma educação para e na diversidade cultural. Por meio das contradições dos sujeitos pesquisados, que transitam entre os discursos de ódio e os discursos benevolentes, a diferença é concebida como sinônimo de desigualdade, devendo ser integrada até sua homogeneização. De tal modo, proporemos, com o presente estudo, a potência da não-identidade para a construção de estratégias pedagógicas de valorização da diferença, reforçando a luta antirracista/antissexista e questionando as relações baseadas em preconceitos e comportamentos discriminatórios.

Through data collected by teachers from public schools in the state of Rio Grande do Sul/Brazil, this paper aims to problematize the obstacles to an ethical of differences and the full intercultural coexistence in a presupposed education to and in cultural diversity. Through the contradictions of the individuals - who move between hate speeches and benevolent speeches the difference is conceived as synonymous of inequality and should be integrated and homogenized. In this study, we propose consider the power of non-identity for construction of pedagogical strategies of valorization of differences, reinforcing the anti-racist/anti-sexist struggle and questioning relationships based on prejudice and discriminatory behavior.

Cet article vise à discuter, à travers les données recueillies auprès des enseignants/es des écoles publiques de l'état de Rio Grande do Sul Brésil, les obstacles à les différences éthiques et la coexistence interculturelle à plein repose sur une éducation à la et pour diversité culturelle. À travers les contradictions des individus qui se déplacent entre les discours de haine et les discours bienveillants, la différence est conçu comme synonyme de l'inégalité et devrait être intégrée à l'homogénéisation. Donc, nous propose, avec la présente étude, la puissance de la nonidentité pour la construction de stratégies pédagogiques de la valorisation des différences, le renforcement de la lutte contre le racisme/sexisme et le questionnement des relations fondées sur des préjugés et des comportements discriminatoires.

\section{INDEX}

Mots-clés: La diversité culturelle; la politique publique; post-identité logique; professeur; éducation de base

Keywords: Cultural diversity, public policy, post-identity logical, teachers, basic education Palavras-chave: Diversidade cultural, políticas públicas, lógicas pós-identitárias, professoras/es, educação básica 


\section{AUTHORS}

\section{CÉLIA ELIZABETE CAREGNATO}

Professora da Faculdade de Educação e do Programa de Pós-Graduação em Educação da Universidade Federal do Rio Grande do Sul. Endereço de correspondência: Faculdade de Educação - Prédio 12201 - Av. Paulo Gama, s/n CEP 90046-900 Brasil celia.caregnato@gmail.com

\section{PÂMELA MARCONATTO MARQUES}

Doutoranda pelo Programa de Pós-Graduação em Sociologia da Universidade Federal do Rio Grande do Sul. Bolsista do CNPq. Endereço de correspondência: Faculdade de Educação - Prédio 12201 - Av. Paulo Gama, s/n CEP 90046-900 Brasil pmarconatto@gmail.com

\section{GREGORY DA SILVA BALTHAZAR}

Doutorando pelo Programa de Pós-Graduação em Educação da Universidade Federal do Rio Grande do Sul. Bolsista do CNPq. Endereço de correspondência: Faculdade de Educação - Prédio 12201 - Av. Paulo Gama, s/n CEP 90046-900 Brasil

gsbalthazar@gmail.com 